\title{
Pasture evapotranspiration as indicators of degradation in the Brazilian Savanna. A case study for Alto Tocantins watershed
}

\author{
Ricardo G. Andrade ${ }^{* a}$, Antônio H. de C. Teixeira ${ }^{\mathrm{a}}$, Edson E. Sano ${ }^{\mathrm{b}}$, Janice F. Leivas ${ }^{\mathrm{a}}$, Daniel de C. \\ Victoria $^{a}$, Sandra F. Nogueira ${ }^{\mathrm{a}}$ \\ ${ }^{\mathrm{a}}$ Embrapa Monitoramento por Satélite, Campinas, São Paulo, Brazil; ${ }^{\mathrm{b}}$ Embrapa Cerrados, BR-020, \\ Planaltina, Distrito Federal, Brazil
}

\begin{abstract}
The Alto Tocantins watershed, located in the Brazilian Savanna (Cerrado biome), is under an intense land use and occupation process, causing increased pressure on natural resources. Pasture areas in the region are highly relevant to the rational use of natural resources in order to achieve economic and environmental sustainability. In this context, remote sensing techniques have been essential for obtaining information relevant to the assessment of vegetation conditions on a large scale. This study aimed to apply this tool in conjunction with field measurements to evaluate evapotranspiration (ET) against pasture degradation indicators. The SAFER algorithm was applied to estimate ET using MODIS images and weather station data from year 2012. Results showed that ET was lower in degraded pastures. It is noteworthy that during low rainfall period, ET values were $22.2 \%$ lower in relation to non-degraded pastures. This difference in ET indicates changes in the partition of the energy balance and may impact the microclimate. These results may contribute to public policies that aim to reduce the loss of the productive potential of pastures.
\end{abstract}

Keywords: evapotranspiration, vegetation, land use, SAFER.

\section{INTRODUCTION}

The Alto Tocantins watershed undergoes increasing changes in land use and occupation with the expansion of the agricultural frontier. In Brazil, livestock is one of the agricultural activities responsible for thousands of direct and indirect jobs and has a significant share of the gross domestic product (GDP). However, it is essential to combine development and economic growth with environmental sustainability, especially because a significant portion of cultivated pastures show indications of degradation.

In this context, the application of remote sensing techniques can in the diagnosis and development of indicators related to economic and environmental sustainability of pasture areas, especially when dealing with large areas. Some studies have successfully applied orbital remote sensing data to identify and monitor plant conditions using vegetation index such as the Normalized Difference Vegetation Index (NDVI), often used due to its sensitivity to biophysical characteristics of vegetation and its applications in monitoring of land cover and land use $[1,2]$.

NDVI can be used to obtain environmental indicators of pasture conditions, in land use diagnosis and in planning for the sustainable use of natural resources. Furthermore, estimates of evapotranspiration using remote sensing techniques can also be a good indicator of vegetation conditions on a large scale, in this case, through the use of algorithms and models $[3,4]$.

\footnotetext{
*ricardo.andrade@embrapa.br; phone 0055 193211-6200; Fax: 0055 193211-6222; www.cnpm.embrapa.br
} 
The SAFER (Simple Algorithm For Retrieving Evapotranspiration) is a simplified algorithm which has shown good results in the estimation of evapotranspiration on a large scale [4]. An advantage of this algorithm is that it does no require the use of a thermal band and can be implemented with meteorological data from different types of stations (agrometeorological, conventional and automatic). This important feature allows for the evaluation of historical trends of the energy balance components and water productivity on a large scale and over the years, given that the use of automatic meteorological stations are relatively recent advances in instrumental technology [5].

In this context, this study aimed to use data from the MODIS sensor to obtain classes indicative of degraded pastures in the Alto Tocantins watershed as well as to apply the SAFER algorithm in conjunction with field measurements in order to analyse the evapotranspiration (ET) as an indicative for degradation of the productive potential of pasture.

\section{MATERIAL AND METHODS}

The study area includes a portion of the Alto Tocantins watershed, Goiás State (Figure 1), located in the Brazilian Savanna (Cerrado biome). In this region, air temperature and rainfall ranges from 21 to $25^{\circ} \mathrm{C}$ and 1100 to $1700 \mathrm{~mm}$.

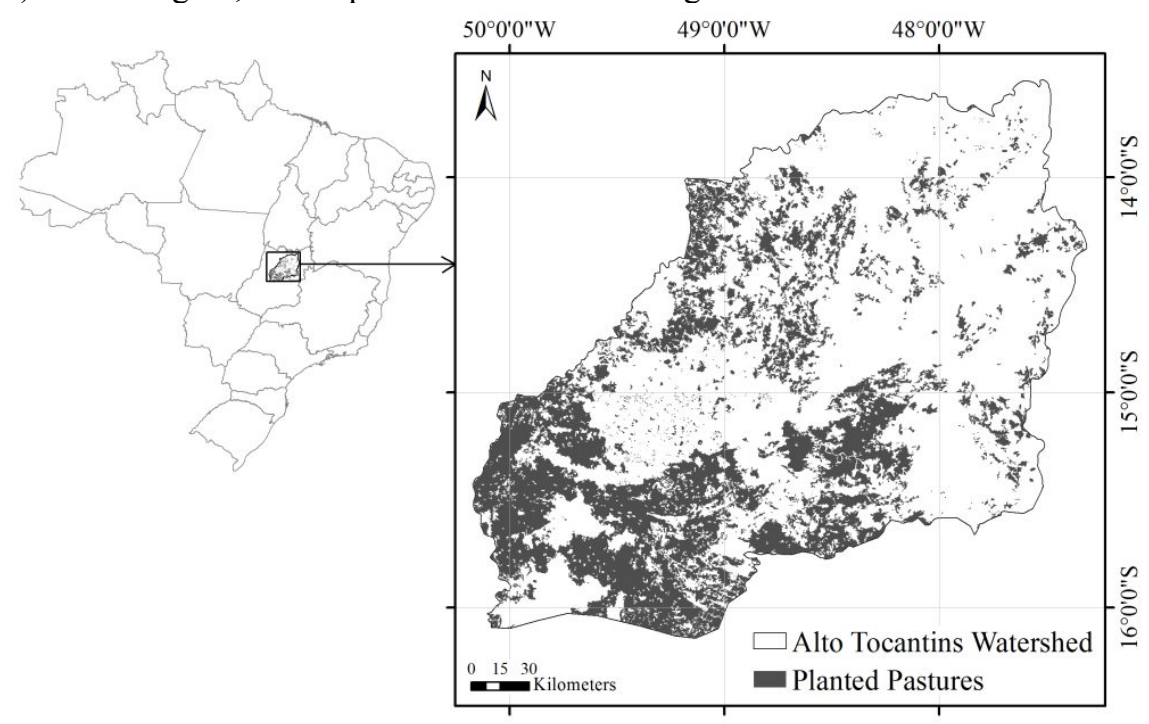

Figure 1. Location of the Alto Tocantins watershed with the identification of planted pastures.

For mapping degraded and non-degraded pastures, the normalized difference vegetation index (NDVI) from the Moderate Resolution Imaging Spectroradiometer (MODIS) for the period January 2002 and December 2012 was used. The NDVI time series was processed according to the following sequence: pre-processing, calculation of time series alteration rate, and linear regression analysis.

The linear regression analysis was used to estimate the tendency of change of each grid point. Stow et al. [6] adopted this method to simulate the rate of vegetation greenness change. For each pixel, the maximum annual NDVI linear tendency during the period of the study was estimated through the application of ordinary regression of minimum squares. The slope (Eq. 1) is the slope coefficient of the regression line adjusted for each pixel. Positive slopes indicate that vegetation is in process of regeneration, while negative slopes indicate the presence of some degradation process in pasture [1].

$$
\text { Slope }=\frac{\sum_{i=1}^{n}\left(Y_{i}-\bar{Y}\right)\left(Y_{N D V I_{i}}-\overline{Y_{N D V I}}\right)}{\sum_{i=1}^{n}\left(Y_{i}-\bar{Y}\right)^{2}}
$$

Where: $\mathrm{n}=10$, the number of years in the time series (2002-2012); $\mathrm{i}=$ year 1 for 2002, year 2 for 2003, and so on; and $Y_{N D V I_{i}}=$ the maximum NDVI value on year $i$. 
The slope coefficients were used to evaluate the NDVI changes throughout time. Indications of degradation are observed when the slope is less than -0.001 (Liu et al., 2010). Thus, two were established for cultivated pastures. Pastures were classified as degraded when the slope was less than -0.001 and non-degraded for slopes greater than or equal to -0.001 .

Simple Algorithm For Evapotranspiration Retrieving (SAFER) was applied and estimated albedo and evapotranspiration (ET) for each pasture degradation class. For this, we used NDVI-MODIS products for year 2012 together with data from weather stations available at the National Institute of Meteorology (INMET) in Brazil.

In SAFER, surface albedo $\left(\alpha_{0}\right)$ was estimated from MODIS bands 1 and 2 with a spatial resolution of $250 \mathrm{~m}$ :

$\alpha_{0}=a+b \alpha_{1}+c \alpha_{2}$

Where, $\alpha_{1}$ and $\alpha_{2}$ are bands 1 and 2 spectral reflectance and a, b and c are regression coefficients with values of 0.08 , 0.41 and 0.14 , respectively (Teixeira et al. 2013).

For the surface temperature $\left(\mathrm{T}_{\mathrm{o}}\right)$, the radiation balance equation was used [7]:

$T_{o}=\sqrt[4]{\frac{R_{G}-\alpha_{o} R_{G}+\varepsilon_{A} \sigma T_{a}^{4}-R_{n}}{\varepsilon_{S} \sigma}}$

Where $\mathrm{R}_{\mathrm{G}}$ and $\mathrm{T}_{\mathrm{a}}$ are respectively the daily values of the incident solar radiation and mean air temperature at the weather stations, $\mathrm{Rn}$ is the daily net radiation, $\varepsilon_{\mathrm{A}}$ and $\varepsilon_{\mathrm{S}}$ are respectively the atmospheric and surface emissivities, and $\sigma$ is the Stefan-Boltzmann constant $\left(5.67 \times 10-8 \mathrm{~W} \mathrm{~m}^{-2} \mathrm{~K}^{-4}\right)$.

$\varepsilon_{\mathrm{A}}$ and $\varepsilon_{\mathrm{S}}$ were calculated as follows [8-9]:

$$
\begin{aligned}
& \varepsilon_{A}=a_{A}+\left(\ln \tau_{S}\right)^{b_{A}} \\
& \varepsilon_{S}=a_{S}+(\ln N D V I)^{b_{S}}
\end{aligned}
$$

Where $\tau_{\mathrm{S}}$ is the short-wave transmissivity calculated as the ratio of $\mathrm{R}_{\mathrm{G}}$ to the incident solar radiation at the top of the atmosphere, and $\mathrm{a}_{\mathrm{S}}, \mathrm{b}_{\mathrm{S}}, \mathrm{a}_{\mathrm{A}}$ and $\mathrm{b}_{\mathrm{A}}$ are regression coefficients taken as $0.06,1.00,0.94$ and 0.10 according to [9].

Daily $\mathrm{Rn}$ can be described by the 24-hour values of net shortwave radiation, with a correction term for net longwave radiation for the same time-scale [9]:

$$
R n=\left(1-\alpha_{0}\right) R_{G}-a_{l} \tau_{s w}
$$

Where $\mathrm{a}_{1}$ is the regression coefficient of the relationship between net long wave radiation and $\tau_{\mathrm{sw}}$ on a daily scale.

Because of the thermal influence on longwave radiation via the Stephan Boltzmann equation, a previous study investigated whether the variations of the $a_{1}$ coefficient from Eq. 6 could be explained by variations in 24 hours $T_{a}$ [9]:

$a_{l}=d T_{a}-e$

Where $\mathrm{d}$ and e are regression coefficients found to be 6.99 and 39.93 respectively for the Brazilian Northeast conditions. The SAFER algorithm is used to model the instantaneous values of the ratio ET/ET, which is then multiplied by the daily values of $\mathrm{ET}_{\mathrm{o}}$ from the weather stations to estimate the daily ET large-scale values:

$$
\frac{E T}{E T_{o}}=\left\{\exp \left[\beta+\eta\left(\frac{T_{0}}{\alpha_{0} N D V I}\right)\right]\right\} f_{c}
$$

Where $\mathrm{ET}_{0}$ is the reference evapotranspiration obtained from weather stations calculated by the Penman-Monteith [10] and $\beta$ e $\eta$ are the original regressions coefficients, 1.9 and -0.008 [9], respectively. A correction factor $\left(\mathrm{f}_{\mathrm{c}}=\mathrm{ET}_{\mathrm{o} \text { year }} /\right.$ 5) was applied, where $\mathrm{ET}_{\mathrm{o}}$ year is the reference evapotranspiration for the study area in 2012, and $5 \mathrm{~mm}$ is the corresponding reference evapotranspiration for the period of modelling in the semi-arid region where the model was originally developed.

\section{RESULTS AND DISCUSSION}

Indications of degradation along the pasture areas (red) in the Alto Tocantins watershed were observed. These indications correspond to approximately 24\% (383 $290 \mathrm{ha}$ ) of planted pastures areas (Figure 2). These results are in agreement with a study by Andrade et al. [11], for pasture areas in the Goiás State, using Spot-Vegetation (VGT-S10) NDVI products from the 2006 to 2011. 


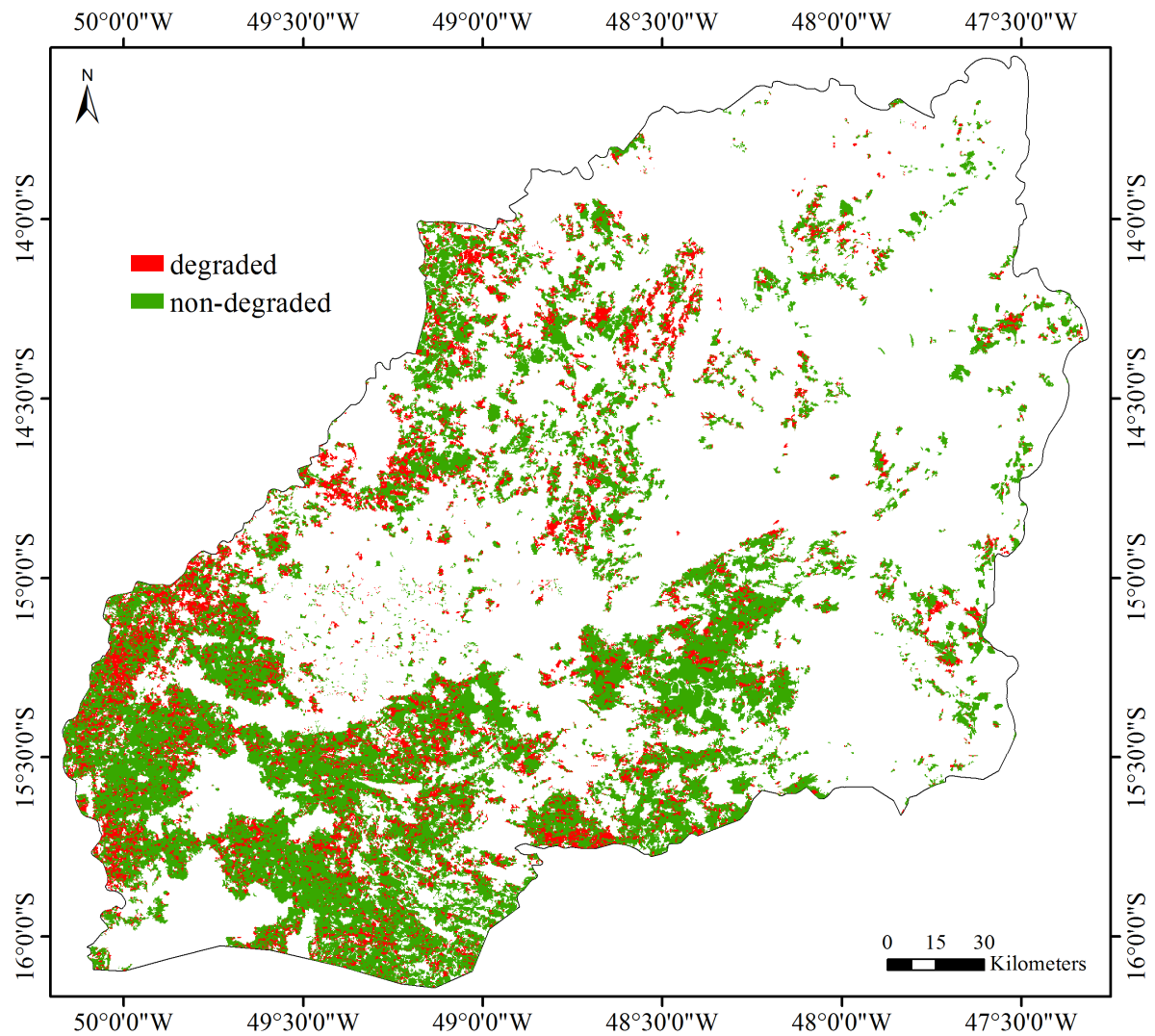

Figure 2. Indications of degradation in planted pastures in the Alto Tocantins watershed in Brazilian Savanna.

ET of the pastures areas in the Alto Tocantins watershed in Brazilian Savanna is shown in Figure 3. Maximum ET values of $5.0 \mathrm{~mm} \mathrm{~d}^{-1}$ can be observed from January to March 2012, however, during this period, due to the high spatial variability of ET, mean value was $2 \mathrm{~mm} \mathrm{~d}^{-1}$. It is noteworthy that from May to October, ET was less than $1.50 \mathrm{~mm} \mathrm{~d}^{-1}$ in practically all pasture area. In this case, ET is influenced by drought, the reduction in pasture biomass and productivity, because both plant transpiration and soil evaporation are restricted due to the suboptimal water supply in the soil. ET will be reduced when more than $50 \%$ soil available water has been used [12]. Thus, we note that ET in pastures areas is strongly dependent on soil moisture, ie, low water availability in the soil influences the amount of energy that is partitioned and possibly decreases the amount of energy to the latent heat flux and increases the partition of energy for sensible heat flux $[13,14]$. 

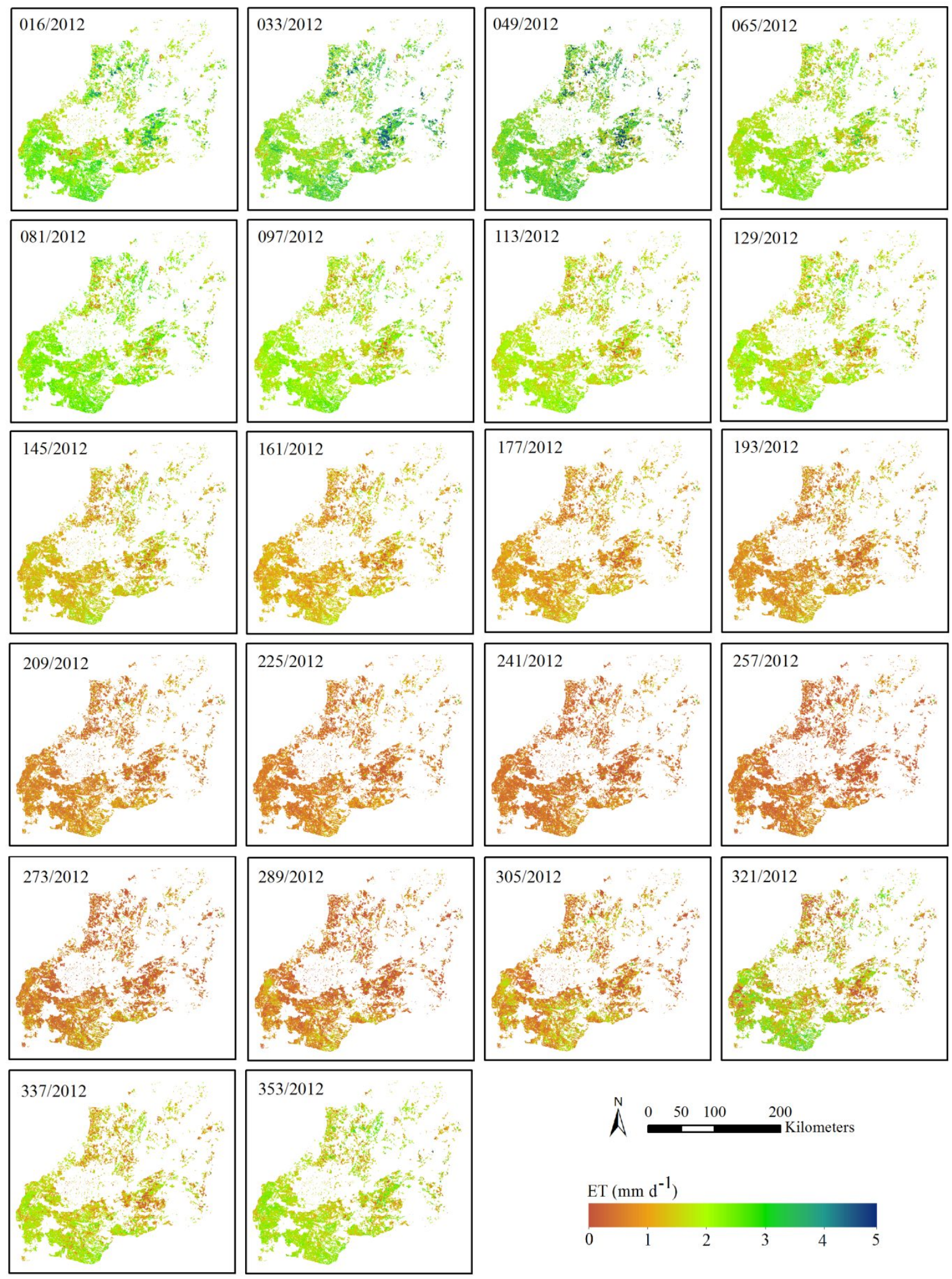

Figure 3. Evapotranspiration of pastures areas in the Alto Tocantins watershed in Brazilian Savanna. 
For classes of planted pastures presented in Figure 2, we estimated the actual daily evapotranspiration (ET) using MODIS products (synthesis of 16 days) for the year 2012 (Figure 4). For all dates, ET was lower in pastures with indications of degradation. Furthermore, it is noteworthy that the largest differences of ET between pastures areas with and without indications of degradation happened in the months September-October. The smallest differences were observed in the months of February and March. Factors related to pasture management (eg over grazing) and spatiotemporal heterogeneity of rainfall throughout the year, may have influenced these results.

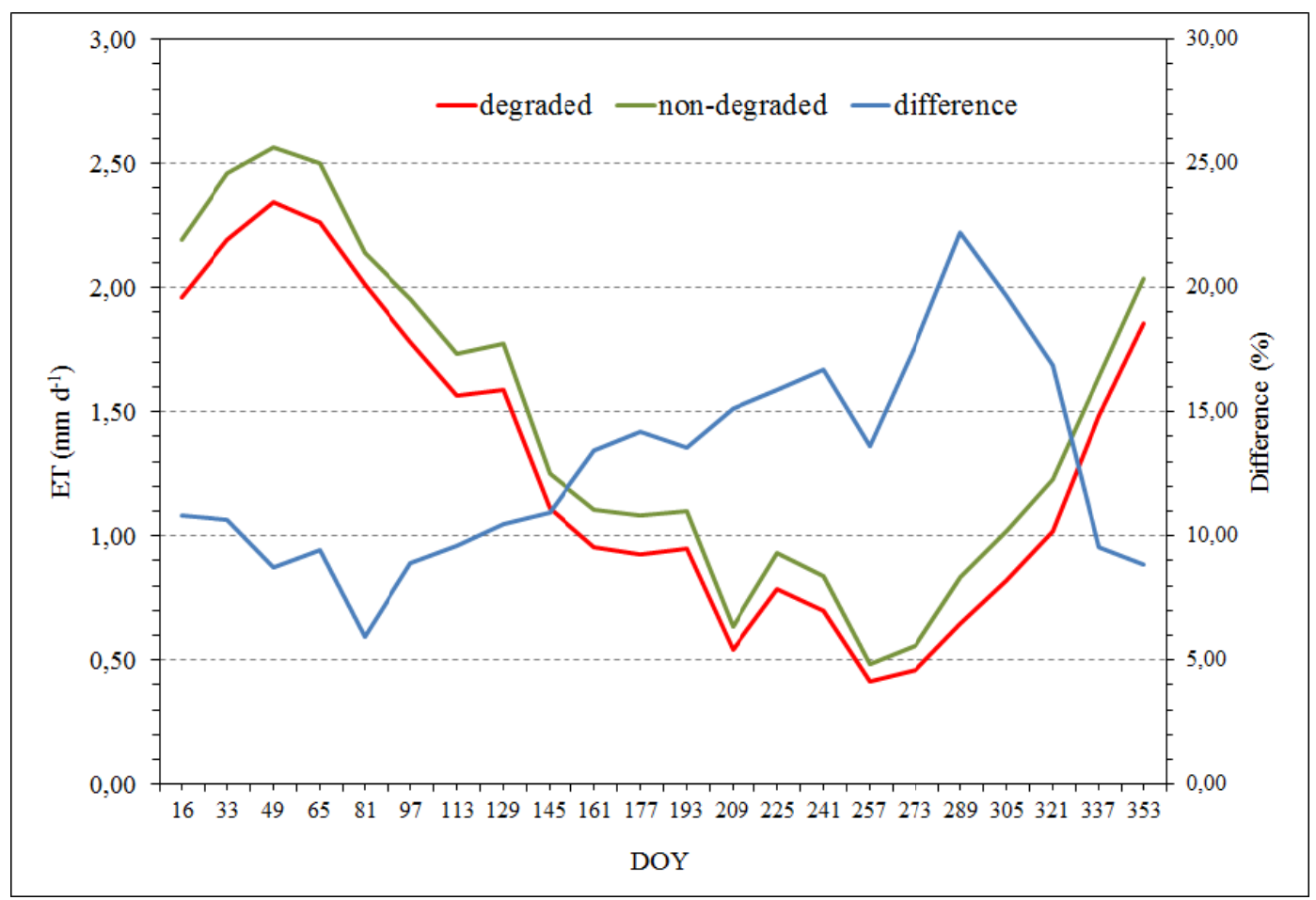

Figure 4. Average evapotranspiration (ET), in the year 2012, for the pasture areas with and without indications of degradation and percent difference between the average ET values.

\section{CONCLUSIONS}

We conclude that, in the Alto Tocantins watershed, significant differences were observed between the ET of pastures with and without signs of degradation. These differences were more pronounced during the dry periods, when ET values were $22.2 \%$ lower.

These results indicate changes in the partition of the energy balance in accordance with the loss of pasture productive potential, and this effect can be considerable since $24 \%$ of pastures in the study area showed indications of degradation. It is hoped that these results may contribute to public policy initiatives that aim to reduce the loss of pasture productive potential in the Alto Tocantins watershed.

\section{ACKNOWLEDGEMENTS}

Brazilian Agricultural Research Corporation (EMBRAPA) is acknowledged for the financial support to the GeoRastro and GeoDegrade projects; and the Brazilian National Meteorological Institute (INMET) for the availability of weather data. 


\section{REFERENCES}

[1] Liu, S., Wang, T., Guo, J., Qu, J., An, P. "Vegetation change based on SPOT-VGT data from 1998-2007, northern China". Environ. Earth Sci., 60, 1459-1466 (2010).

[2] Leivas, J. F., Andrade, R. G., Victoria, D. C., Torresan, F. E., Vicente, L. E., Bolfe, E. L., Barros, T. R. "Spectral response variations as indicators of seasonal floods in Pantanal using Spot-Vegetation time series". Geografia (Rio Claro. Impresso), 38, 123-137 (2013).

[3] French, A. N., Jacob, F., Anderson, M. C., Kustas, W. P., Timmermans, W., Gieske, A., Su, Z., Su, H., Mccabe, M. F., Prueger, J., Brunsell, N. "Surface energy fluxes with the advanced spaceborne thermal emission and reflection radiometer (ASTER) at the Iowa 2002 SMACEX site (USA)". Remote Sens. Environ., 99, 55-65 (2005).

[4] Teixeira, A. H. de C., Scherer-Warren, M., Hernandez, F. B. T., Andrade, R. G., Leivas, J. F. "Large-Scale Water Productivity Assessments with MODIS Images in a Changing Semi-Arid Environment: A Brazilian Case Study", Rem. Sens., 55783-5804 (2013).

[5] Teixeira, A. H. de C., Hernandez, F. B. T., Lopes, H. L., Scherer-Warren, M., Bassoi, L. H. "Modelagem espaçotemporal dos componentes dos balanços de energia e de água no Semiárido brasileiro". Documentos: 99 Embrapa Monitoramento por Satélite, (2013).

[6] Stow, D., Daeschner, S., Hope, A., Douglas, D., Petersen, A., Myneni, R., Zhou, L., Oechel, W. "Variability of the seasonally integrated normalized difference vegetation index across the north slope of Alaska in the 1990s". Int. J. Rem. Sens., 24, 1111-1117 (2003).

[7] Teixeira, A.H. de C., Hernandez, F.B.T., Andrade, R.G., Leivas, J.F., Victoria, D. de C., Bolfe, E.L. "Irrigation performance assessments for corn crop with Landsat images in the São Paulo state, Brazil”. Proc. INOVAGRI, 739-748 (2014).

[8] Teixeira, A. H. de C. "Determining regional actual evapotranspiration of irrigated and natural vegetation in the São Francisco river basin (Brazil) using remote sensing an Penman-Monteith equation," Rem. Sens., 2, 1287-1319 (2010).

[9] Teixeira, A.H. de C., Hernandez, F.B.T., Lopes, H.L., Scherer-Warren, M., Bassoi, L.H. "A Comparative Study of Techniques for Modeling the Spatiotemporal Distribution of Heat and Moisture Fluxes in Different Agroecosystems in Brazil". In: George G. Petropoulos. (Org.). Remote Sensing of Energy Fluxes and Soil Moisture Content. 1ed.Boca Raton, Florida: CRC Group, Taylor and Francis, 169-191 (2014).

[10] Allen, R.G., Pereira, L.S., Raes, D., Smith, M. "Crop Evapotranspiration: Guidelines for Computing Crop Water Requirements". Food and Agriculture Organization of the United Nations: Rome, Italy (1998).

[11] Andrade, R. G., Leivas, J. F., Garçon, E. A. M., Silva, G. B. S., Gomes, D., Vicente, L. E., Bolfe, E. L., Victoria, D. C. "Indicativo de degradação de pastagens a partir de dados Spot Vegetation". Proc. Simpósio Brasileiro de Sensoriamento Remoto/INPE, 16, 6917-6922 (2013).

[12] Kerr, J. P., McPherson, H. G. "Evapotranspiration and physiological responses to water stress of several pasture and crop species". Proc. N.Z. GRASSLAND ASSOCIATION, 39, 70-78 (1977).

[13] Gu, L., Meyers, T., Pallardy, S. G., Hanson, P. J., Yang, B., Heuer, M., Hosman, K. P., Riggs, J. S., Sluss, D., Wullschleger, S. D. "Direct and indirect effects of atmospheric conditions and soil moisture on surface energy partitioning revealed by a prolonged drought at a temperate forest site". J. Geophys. Res., 111, 16102 (2006).

[14] Ham, J. M., Heilman, J. L., Lascano, R. J. "Soil and canopy energy balances of a row crop at partial cover". Agron. J., 83, 744-753 (1991). 